\title{
EFFECT OF SUBCUTANEOUS RECOMBINANT HUMAN ERYTHROPOIETIN ON BLOOD PRESSURE IN PRE-DIALYSIS CHRONIC KIDNEY DISEASE (CKD) PATIENTS
}

\author{
Muhammad Sajid Hussain, Qasim Raza*, Muhammad Omer Aamir**, Nadia Murtaza***, Sadia Naureen****, \\ Mehwish Razzaq***** \\ Army Selection \& Recruitment Centre, Multan Pakistan, ${ }^{*}$ Quaid-e-Azam International Hospital, Islamabad Pakistan, ${ }^{* *}$ Combined Military \\ Hospital Rawalakot/National University of Medical Sciences (NUMS) Pakistan, ${ }^{* * *}$ Combined Military Hospital Peshawar/National \\ University of Medical Sciences (NUMS) Pakistan, ${ }^{* * * *}$ Allied Hospital, Faisalabad Pakistan, ${ }^{* * * *}$ Army Medical College/National University of \\ Medical Sciences (NUMS) Rawalpindi Pakistan
}

\begin{abstract}
Objective: To determine the effect of subcutaneous recombinant human erythropoietin on blood pressure in predialysis chronic kidney disease (CKD) patients.

Study Design: Case-series descriptive study.

Place and Duration of Study: Combined Military Hospital Peshawar, from Mar 2016 to Sep 2016.

Methodology: A total of 100 cases were enrolled. Inclusion criteria was patients of 18 to 60 years of both gender \& estimated glomerular filtration rate (eGFR) below $30 \mathrm{~mL} / \mathrm{min} / 1.73 \mathrm{~m}^{2}$ having $\mathrm{Hb}<10 \mathrm{~g} / \mathrm{dL}$ and pre-dialysis while Exclusion Criteria was pregnancy or lactation, BP more than 140/90 $\mathrm{mmHg}$, patients on Haemodialysis and worsening renal function. Baseline BP, body weight and eGFR of anaemic chronic kidney disease patients were recorded prior to EPO Alpha therapy. Erythropoiesis-stimulating agents (ESAs) i.e. EPO Alpha (50-100 Units/kg thrice or once weekly) was administered subcutaneously. Subsequent blood pressure, body weight and eGFR monitoring was done after 2 and 4 weeks post EPO Alpha injection.

Results: Mean age range was 46.71 years with range of 20-60 years, $73(73 \%)$ were male while $27(27 \%)$ were females. Mean \pm SD for other quantitative variables like eGFR was $23.12 \pm 5.28, \mathrm{Hb}$ levels $(\mathrm{g} / \mathrm{dL})$ was $8.62 \pm 0.85$, Weight $(\mathrm{kg})$ was $56.66 \pm 6.62$ and duration of CKD was $9.87 \pm 4.02$. Frequency of Hypertension (post EPO) was 2 $(2 \%)$ and $p$-value was 0.453 .

Conclusion: We concluded that the frequency of hypertension in pre-dialysis patients with chronic kidney disease (CKD) receiving recombinant human erythropoietin (rhEPo) subcutaneously (SC) in low doses, is very low, so rhEPo can be used subcutaneously for treatment of anemia in pre-dialysis CKD patients.
\end{abstract}

Keywords: Anemia, Chronic kidney disease, Erythropoietin, Hypertension.

This is an Open Access article distributed under the terms of the Creative Commons Attribution License (http://creativecommons.org/licenses/by/4.0), which permits unrestricted use, distribution, and reproduction in any medium, provided the original work is properly cited.

\section{INTRODUCTION}

According to studies, approximately $71-95 \%$ of adult patients having chronic kidney disease (CKD) suffer from hypertension ${ }^{1-2}$. High blood pressure increases cardiovascular morbidity and mortality and also leads to a rapid decline in renal function ${ }^{3}$. Therefore, keeping blood pressure readings less than $140 / 90 \mathrm{mmHg}$ is recommended in current guidelines for patients with $\mathrm{CKD}^{4}$. The production of endogenous erythropoietin falls with worsening of renal function and most of CKD patients with anemia are usually given erythropoiesis-stimulating agents (ESAs).

Correspondence: Dr Muhammad Omer Aamir, Combined Military Hospital, Rawalakot Pakistan

Received: 07 Mar 2019; revised received: 20 Jul 2019; accepted: 22 Jul 2019
Patients on dialysis who were treated with higher doses of ESA showed an increased mortality mainly from cardiovascular causes in some observational studies ${ }^{5}$. The mechanism which causes these more frequent cardiovascular events and mortality has not been entirely identified yet. Therefore, different hypotheses have been suggested, but increase in risk of cardiovascular events due in rise in blood pressure by ESAs therapy is an important and widely accepted theory ${ }^{6}$.

During late 1980s at the time of introduction of ESAs in patients on haemodialysis, ESA induced hypertension was first reported and hypertension developed in approximately 20 to 30 percent of patients after ESA therapy ${ }^{7}$. However, with the passage of time nephrologists have 
learnt to prevent these side effects by slowly increasing haemoglobin levels with lower doses of ESAs. The actual blood pressure may remain stable during treatment with ESAs in clinical practice, with or without adjusting the antihypertensive medication ${ }^{8}$.

Data on control of blood pressure in patients having CKD is limited and the pre-dialysis patients are under-represented in the available studies. Most importantly, complete information regarding the effect of treatment with ESAs on blood pressure of patients is lacking 9 . Therefore, the rationale of this study is to determine whether treatment with ESAs is associated with rise in blood pressure or not.

\section{METHODOLOGY}

This case-series descriptive study was conducted at Combined Military Hospital Peshawar from March 2016 to September 2016. Sample size (n) of 100 patients was calculated for this study using the WHO Sample size calculator for estimating a population proportion with specified absolute precision whereas confidence level of $95 \%$ and absolute precision of $0.08 \%$ was used with anticipated population size $20 \%$ and Sampling Technique was non-probability consecutive ${ }^{10}$. A total of 100 cases fulfilling the inclusion and exclusion criteria were enrolled. Inclusion Criteria included Patients of 18 to 60 years of both gender \& estimated glomerular filtration rate (eGFR) $<30$ $\mathrm{mL} / \mathrm{min} / 1.73 \mathrm{~m}^{2}$ having $\mathrm{Hb}<10 \mathrm{~g} / \mathrm{dL}$ and predialysis while exclusion criteria included pregnancy or lactation, baseline BP more than 140/90 $\mathrm{mmHg}$, patients on Haemodialysis, worsening renal function (Decrease in eGFR $>10 \mathrm{ml} / \mathrm{min}$ / $1.73 \mathrm{~m}^{2}$ or development of signs of fluid overload measured after 2 and 4 weeks of starting ESA. Baseline blood pressure, body wei-ght and eGFR of anaemic chronic kidney disease patients were recorded prior to commencement of EPO Alpha therapy. ESA i.e. EPO Alpha (50-100 Units/kg thrice or once weekly) was administered subcutaneously. Subsequent blood pressure, body weight and eGFR monitoring was done after 2 and 4 weeks post EPO Alpha injection.
Data entry and analysis were done by using SPSS 20. For both qualitative and quantitative variables, the descriptive statistics were calculated. For qualitative variables like gender and hypertension post EPO injection; frequency and percentages were calculated. For quantitative variables like age, GFR, Body weight, $\mathrm{Hb}$, Duration mean and \pm standard deviation was calculated. Data was presented as Pie charts. Stratification was applied to control effect modifiers like age, weight \& duration and Chi Square test (Post Stratification) was also applied and $p$-value $\leq 0.05$ was considered as significant.

\section{RESULTS}

A total of 100 cases which fulfilled the given inclusion/exclusion criteria were enrolled to determine the frequency of hypertension in predialysis patients having chronic kidney disease being treated with recombinant human erythropoietin.

Age distribution of the patients was done showing that $8(8 \%)$ were between $20-29$ years of age, 14 (14\%) were between 30-39 years, 36 (36\%) between 40 to 49 years of age, 41 (41\%) between 50-59 years and 1 (1\%) between 60 \& above years and mean \pm SD was then calculated as $46.71 \pm$ 9.55 years. Patients were also distributed according to gender, which showed that $73(73 \%)$ were male and $27(27 \%)$ were females. Mean \pm SD for other quantitative variables like eGFR, $\mathrm{Hb}$ levels (g/dL), Weight $(\mathrm{kg})$ and duration of CKD (years) were also calculated (table-I).

Table-I: Mean \pm SD for quantitative variables $(\mathbf{n}=100)$.

\begin{tabular}{c|c|c|c|c}
\hline & $\begin{array}{c}\text { eGFR (ml/ } \\
\mathbf{m i n} / \mathbf{1 . 7 3} \\
\mathbf{m}^{\mathbf{2}} \mathbf{)}\end{array}$ & $\begin{array}{c}\mathbf{H b} \\
\mathbf{( g / d L )}\end{array}$ & $\begin{array}{c}\text { Weight } \\
\mathbf{( k g )}\end{array}$ & $\begin{array}{c}\text { Duration } \\
\text { of CKD } \\
\text { (years.) }\end{array}$ \\
\hline $\mathrm{N}$ & 100 & 100 & 100 & 100 \\
\hline Mean & 23.1277 & 8.6220 & 56.66 & 9.87 \\
\hline $\mathrm{SD}$ & 5.28816 & 0.85299 & 6.627 & 4.024 \\
\hline
\end{tabular}

Frequency of Hypertension (post EPO) was $2(2 \%)$ (table-II). The data was stratified for age, weight and duration of CKD to control the effect modifiers (table-III, IV \& V). 
The overall $p$-value was calculated using chi square test which was 0.453 . This showed that $p$-value was $>0.05$ which was insignificant. Thus recombinant human erythropoietin (EPO) given subcutaneously and in low dose does not cause hypertension.

Table-II: Percentage of hypertension (post epo) $(\mathbf{n}=100)$.

\begin{tabular}{l|c}
\hline Hypertension & No. of Patients (\%) \\
\hline Yes & $2(2 \%)$ \\
\hline No & $98(98 \%)$ \\
\hline
\end{tabular}

Table-III: Stratification of hypertension (post epo) with age $(n=100)$.

\begin{tabular}{|c|c|c|c|}
\hline \multirow{2}{*}{$\begin{array}{l}\text { Age Groups } \\
\text { (Years) }\end{array}$} & \multicolumn{2}{|c|}{$\begin{array}{c}\text { Hypertension (Post } \\
\text { Epo) }\end{array}$} & \multirow[t]{2}{*}{$p$-value } \\
\hline & No $(\%)$ & Yes (\%) & \\
\hline $20-29$ & 8 & 0 & \multirow{6}{*}{$\begin{array}{c}0.815 \\
\text { Fisher } \\
\text { Exact test } \\
\text { value: } \\
0.808\end{array}$} \\
\hline $30-39$ & 13 & 1 & \\
\hline $40-49$ & 36 & 0 & \\
\hline $50-59$ & 40 & 1 & \\
\hline $60 \&$ Above & 1 & 0 & \\
\hline Total & $98 \%$ & $2 \%$ & \\
\hline
\end{tabular}

Table-IV: Stratification of hypertension (post epo) with weight $(n=100)$.

\begin{tabular}{l|c|c|c}
\hline \multirow{2}{*}{$\begin{array}{l}\text { Body Weight } \\
\text { Groups (Kg) }\end{array}$} & \multicolumn{2}{|c|}{\begin{tabular}{c} 
Hypertension (Post \\
\multirow{2}{*}{ EPO) }
\end{tabular}} & \multirow{2}{*}{-value } \\
\cline { 2 - 3 } & No (\%) & Yes (\%) & \\
\hline $45-49$ & 21 & 1 & \multirow{2}{*}{0.683} \\
\hline $50-54$ & 11 & 0 & Fisher \\
\hline $55-59$ & 30 & 0 & Exact test \\
\hline $60-64$ & 25 & 1 & value: \\
\hline 65 \& Above & 11 & 0 & 0.684 \\
\hline Total & $98 \%$ & $2 \%$ & \\
\hline
\end{tabular}

Table-V: Stratification of hypertension (post epo) with duration of ckd $(n=100)$.

\begin{tabular}{l|c|c|c}
\hline \multirow{2}{*}{$\begin{array}{l}\text { Duration of } \\
\text { CKD (Years) }\end{array}$} & \multicolumn{2}{|c|}{ Hypertension (Post } & \multirow{2}{*}{$\boldsymbol{p}$-value } \\
\cline { 2 - 3 } & No (\%) & Yes (\%) & \\
\hline $1-5$ & 13 & 0 & 0.260 \\
\hline $6-10$ & 39 & 1 & Fisher \\
\cline { 1 - 2 } $11-15$ & 41 & 1 & Exact test \\
\cline { 1 - 2 } 16 \& Above & 5 & 0 & value: \\
\cline { 1 - 3 } Total & $98 \%$ & $2 \%$ & 0.373 \\
\hline
\end{tabular}

\section{DISCUSSION}

Chronic kidney disease (CKD) is gradually increasing in the South Asian countries like Pakistan and the reason of its spread is multifactorial ${ }^{11-13}$. In the United States, the national
Institute of Diabetes and Digestive and Kidney Disease (NIDDK) reports that 1 in every 10 American adults has some degree of chronic kidney disease. A systematic review of observational studies revealed a global CKD prevalence of approximately $11-13 \%$ worldwide and the majority of cases are found to be Stage $3^{14}$. The See Kidney Disease (SeeKD) targeted screening project found a high proportion of individuals with risk factors for CKD and a high prevalence of unrecognized CKD. Of the 5194 patient screened, $18.8 \%$ had unrecognized CKD (estimated eGFR $<60 \mathrm{~mL} /$ $\mathrm{min} / 1.73 \mathrm{~m}^{2}$ ) and about $13.8 \%$ had stage $3 \mathrm{a}$ CKD $\left(\mathrm{eGFR} 45-60 \mathrm{~mL} / \mathrm{min} / 1.73 \mathrm{~m}^{2}\right)^{15}$. Anemia is very common in patients with CKD and it may be responsible for few symptoms associated with decline in kidney function like fatigue, dyspnea, decreased exercise tolerance and depression. The prevalence of anemia increased with the stage of CKD, from $8.4 \%$ at stage 1 to $53.4 \%$ at stage- 5 $\mathrm{CKD}^{16}$. Anemia is one of the leading cause of increased morbidity and mortality due to cardiovascular diseases in CKD patients. Moreover, it also increases the risk of hospitalization and prolongs hospital stay in these patients. Erythropoiesis-stimulating agents like recombinant human erythropoietin (rhEPo) are used to treat the anemia in CKD patients. These agents decrease the requirement for transfusion and improve symptoms related to quality of life, exercise tolerance and most importantly left ventricular hypertrophy (LVH), which is associated with increased mortality. Studies have shown that the SC dose of erythropoietin required to achieve a target $\mathrm{Hb}$ level is approximately 30 percent less than that required with IV administration ${ }^{17}$. Some adverse effects have also been reported when ESAs are used to attain a normal hemoglobin level ${ }^{18-19}$. Hypertension is one of the most common side effect of ESA therapy ${ }^{20-21}$. According to studies, approximately 20 to 30 percent patients who receive erythropoietin intravenously (IV) for the anemia of CKD develop an elevation in diastolic pressure of $10 \mathrm{mmHg}$ or more but there is limited data available regarding association of hypertension with the subcutaneous usage of erythropo- 
ietin especially in predialysis patients. Therefore, this study was conducted to determine the frequency of hypertension in predialysis patients with chronic kidney disease receiving recombinant human erythropoietin (rhEPO) subcutaneously for their anemia.

Our final results were quite similar to the results of study conducted by Watson et al, published in the American Journal of Medicine, and that study demonstrated that recombinant human erythropoietin (rhEPo) given subcutaneously (SC) is an effective and safe therapy for patients with chronic kidney failure who are anemic and who are not receiving dialysis (No significant change in Mean BP was noted in 11 patients with pre-dialysis CKD treated for 12 weeks with low doses of SC recombinant human erythropoietin).

Another such study conducted by Bushra Moiz et al, and published in JCPSP revealed that low doses of subcutaneous (SC) recombinant human erythropoietin (rhEPo) used for the treatment of anemia in CKD, are not associated with significant rise in blood pressure in patients who are not already hypertensive (None out of 12 non hypertensive patients showed increase in BP after low doses of SC recombinant human erythropoietin used for 10 weeks). Therefore, various studies conducted in different populations concluded that predialysis CKD patients can safely use recombinant human erythropoietin (rhEPo) subcutaneously for treatment of anemia, but in low to moderate doses, with low target hemoglobin, to avoid rise in blood pressure associated with ESA therapy.

\section{CONCLUSION}

We concluded that the hypertension in predialysis patients with CKD receiving recombinant human rhEPo SC in low doses, is very low, therefore rhEPo can be used subcutaneously, to treat anemia safely in predialysis patients with CKD.

\section{CONFLICT OF INTEREST}

This study has no conflict of interest to be declared by any author.

\section{REFERENCES}

1. Muntner P, Anderson A, Charleston J, Chen Z, Ford V, Makos G, et al. Hypertension Awareness, Treatment, and Control in Adults With CKD: Results From the Chronic Renal Insufficiency Cohort (CRIC) Study. Am J Kidney Dis 2010; 55(3): 441-51.

2. Sarafidis P, Sharpe C, Wood E, Blacklock R, Rumjon A, AlYassin A, et al. Prevalence, Patterns of Treatment, and Control of Hypertension in Predialysis Patients with Chronic Kidney Disease. Nephron Clin Pract 2012; 120(3): 147-55.

3. De Goeij M, Voormolen N, Halbesma N, de Jager D, Boeschoten E, Sijpkens Y, et al. Association of blood pressure with decline in renal function and time until the start of renal replacement therapy in pre-dialysis patients: a cohort study. BMC Nephrol 2011; 12(1): 38-40.

4. James P, Oparil S, Carter B, Cushman W, Dennison-Himmelfarb $\mathrm{C}$, Handler J, et al. Evidence-based guideline for the management of high blood pressure in adults. J Am Med Assoc 2014; 311(5): 507-10.

5. Zhang Y, Thamer M, Kaufman J, Cotter D, Hernán M. High doses of epoetin do not lower mortality and cardiovascular risk among elderly hemodialysis patients with diabetes. Kidney Int 2011; 80(6): 663-69.

6. Singh A. What is causing the mortality in treating the anemia of chronic kidney disease: erythropoietin dose or hemoglobin level? Curr Opin in Nephrol Hypertens 2010; 19(5): 420-24.

7. Smith K. The cardiovascular effects of erythro-poietin. Cardiovascul Res 2003; 59(3): 538-48.

8. Inrig J, Sapp S, Barnhart H, Patel U, Reddan D, Singh A, et al. Impact of higher hemoglobin targets on blood pressure and clinical outcomes: a secondary analysis of CHOIR. Nephrol Dial Transplant 2012; 27(9): 3606-14.

9. Suttorp M, Hoekstra T, Mittelman M, Ott I, Franssen C, Dekker F. Effect of Erythropoiesis-Stimulating Agents on Blood Pressure in Pre-Dialysis Patients. PLos One 2013; 8(12): e84848.

10. Smith K. The cardiovascular effects of erythropoietin. Cardiovascul Res 2003; 59(3): 538-48.

11. Imran S, Sheikh A, Saeed Z, Khan SA, Malik AO, Patel J et al. Burden of chronic kidney disease in an urban city of Pakistan, a cross-sectional study. J Pak Med Assoc 2015; 65(4): 366-69.

12. Ullah K, Butt G, Masroor I, Kanwal K, Kifayat F. Epidemiology of chronic kidney disease in a Pakistani population. Saudi J Kidney Dis Transpl 2015; 26(1): 1307-10.

13. Alam A, Amanullah F, Baig-Ansari N, Lotia-Farrukh I, Khan FS. Prevalence and risk factors of kidney disease in urban Karachi: baseline findings from a community cohort study. BMC Res Notes 2014; 7(2): 179-82.

14. Hill NR, Fatoba ST, Oke JL, Hirst JA, O'Callaghan CA, Lasserson DS. Global prevalence of chronic kidney disease - a syste-matic review and meta-analysis. PLoS One 2016; 11(7): e0158765-72.

15. Galbraith LE, Ronksley PE, Barnieh LJ, Kappel J, Manns BJ, Samuel SM, et al. The See Kidney Disease Targeted Screening Program for CKD. Clin J Am Soc Nephrol 2016; 11(6): 964-72.

16. Stauffer ME, Fan T. Prevalence of anemia in chronic kidney disease in the United States. PLoS One 2014; 9(1): e84943-46.

17. Wright DG, Wright EC, Narva AS, Noguchi CT, Eggers PW. Association of Erythropoietin Dose and Route of Administration with Clinical Outcomes for Patients on Hemodialysis in the United States. Clin J Am Soc Nephrol 2015; 10(1): 1822-25.

18. Arantes L, Crawford J, Gascon P, Latymer M, Launay-Vacher V, Rolland C, et al. A quick scoping review of efficacy, safety, economic, and health-related quality-of-life outcomes of shortand long-acting erythropoiesis-stimulating agents in the treatment of chemotherapy-induced anemia and chronic kidney 
disease anemia. Critical Reviews in Oncol/Hematol 2018; 129(1): 79-90.

19. Salamin O, Kuuranne T, Saugy M, Leuenberger N. Erythropoietin as a performance-enhancing drug: Its mechanistic basis, detection, and potential adverse effects. Molecul Cellular Endocrinol 2018; 464(2): 75-87.
20. Boyle S, Berns J. Erythropoietin and Resistant Hypertension in CKD. Seminars Nephrol 2014; 34(5): 540-49.

21. Palmer S, Saglimbene V, Mavridis D, Salanti G, Craig J, Tonelli $M$, et al. Erythropoiesis-stimulating agents for anaemia in adults with chronic kidney disease: a network meta-analysis. Cochrane Datab Systemat Rev 2014; 2014(12): CD010590. 